\title{
SOCIAL WORK WITH A DEPRESSED CLIENT
}

\author{
Michaela Šul'ová \\ Department of Social Sciences \\ Catholic University in Ruzomberok \\ 89 Hlavná str., Košice, Slovakia, 04121 \\ michaela.sulova@ku.sk
}

\begin{abstract}
Mental health is a fragile area. One of the frequent psychical illnesses is depression which means decline, uneasiness, anxiety. Many people develop a psychical illness during their life, whereby the triggering mechanism can be different stressful situation. Thus, many people with psychical illness become clients of social services facilities. This way the client comes into contact with social workers, which should be ready for their work (or rather mission) professionally and personally. They should be familiar with a range of approaches, methods and techniques, which they can implement based on the client's individual needs within social intervention, in order to improve the client's quality of life. The aim of our research is to determine what approaches and methods are used in social work with depressed clients. As a research method we use the analysis of professional materials and case studies, which focused on the application of methods of social work with clients with depression. The article has theoretical and research parts. In the theoretical part we introduce the diagnostics and symptoms of depression. In the research part we analyze the approaches and methods, used in social work with a depressed client. Then we present case studies, which are focused on the application of methods of social work with clients with depression.
\end{abstract}

Keywords: depression, client, social work methods, social worker.

\section{Introduction}

The international classification of diseases identifies different areas of diseases, whereby mental and behavioral disorders are marked as " $F$ " and they are grouped as follows: F00-F09: Organic mental disorders including symptomatic, F10-F19: mental and behavioral disorders, caused by the use of psychoactive substances, F20-F29: schizophrenias, schizotypal disorders and delusional disorders, F30-F39: affective disorders - including depression, F40-F48: neurotic disorders, stress related disorders and somatoform disorders, F50-F59: behavioral disorders with bodily disorders and factors, F60-F69: adult personality and behavioral disorders, F70-F79: mental retardation), F80-F89: mental development disorders, F90-F98: behavioral and emotional disorders, usually beginning in childhood and during adolescence, F99-F99: mental disorders not specified [1].

The word depression is of Latin origin and literally means $d e=$ down, premere $=$ press. Thus, depression means decline, uneasiness, anxiety [2]. Often, the true extent of the depressive disease is not determined and people perceive it rather as a weakness. Depressed people are often given the advice to "get a hold of yourself", "don’t work", "it will pass", etc. But this is not truly helpful [3].

\section{Theoretical Framework}

In this part we focus on the characteristics of depression, its diagnostic criteria, types and symptoms.

\section{1. Depression Diagnosis}

Depressive syndromes can be reactive (the cause of the depression is psychologically understandable), endogenous (the mood originated and persists without a motive), symptosomatic (in somatic diseases), etc. [4]. In the past there was also a distinction between an endogenous depression and exogenous/reactive depression. An endogenous depression had a bodily basis, whereby a reactive depression was a reaction to experiences and losses, overload or failure [5].

The current classification distinguishes four basic types of a depressive episode, namely mild, moderate, severe and severe with psychotic symptoms. They are distinguished, based on the number of symptoms: 
- group D:

- depressive mood is present for the majority of the day and almost every day;

- loss of interest or joy from activities once pleasurable;

- loss of energy or increased fatigue;

- group E:

- unjustified remorse or the feeling of unjustified guilt;

- repeated thoughts about death or suicide;

- decreased ability to think, focus, indecisiveness, hesitance;

- decreased psychomotoric pace;

- sleep disorders;

- decreased appetite (loss of weight);

- group F:

- non-psychotic forms cannot include delusions, hallucinations or stupor;

- group G:

- psychotic forms include delusions, hallucinations and stupor.

Mild forms include two symptoms from the D group and one or more symptoms from the E group. Moderate forms must include at least two symptoms from the D group and so many symptoms from the E group, so that the final number of symptoms (D and E combined) would be at least six. Severe non-psychotic forms include all three symptoms of the D group and so many from the E group, so that the final number of symptoms (D and E combined) would be at least eight. Severe psychotic forms must include at least as many symptoms as with the severe non-psychotic form and at least two additional symptoms from the G group [6].

\subsection{Depression Symptoms}

Typical depression symptoms include mood disorders (sadness, inability to experience happiness, loss of interests in any activities, lower motivation for any activity, apathy), thinking and perception disorders (slow thinking, reduced concentration, indecisiveness, loss of self-confidence, feelings of guilt, hopelessness, desire to die, suicidal tendencies) [7, 8].

A depressed person ceases to perceive own value, loses the meaning of everyday activities and things done. Everything is a subject to great negation and especially to feelings of guilt for the inability to change anything. The depressive world is empty also in another sense. It is devoid of meaningful content. It does not contain anything worth experiencing. It is reminiscent of scorched earth; any inner or outer world loses attractiveness and value for the depressed person. A person with depression experiences rejection under certain circumstances as a massive loss of self-confidence, which disturbs his or her regulation of self-respect [9].

Depressive people seem to have tunnel vision. They can't seem to see the beauty of the world or anything positive. As if they would be wearing black glasses, they would look at the world through them and see everything only in a negative way. They also have negative thoughts about themselves and their future [5]. A depressed person loses the ability to get interested in something, to rejoice. Situations and activities, which once brought him or her happiness lose their attractiveness, they become indifferent. When confronted with things that once brought him or her happiness, the person becomes aware of his or her current inability to be happy (anhedonia) and succumbs to hopelessness [10]. Thus, a depressive attitude to life is one, where all situations are perceived as negative. "All or nothing" attitudes - excessive generalization - "my friend disappointed me, therefore everyone is bad" - are almost inviolable. An ill person with severe depression sometimes remains in his or her attitude of "the worse I get, the better I am" (the more I understand myself). Trying to talk him or her into seeing the glass as half empty is of little use and risky [11].

Often, the person also complaints of physical problems, such as insomnia or increased sleepiness, decreased or increased appetite, decreased vitality, feeling of heartache or breathing difficulties [12]. Depressed people are not capable of quality relaxation, they don't find escape even in sleep. Their sleep is often of poor quality, interrupted, short or prematurely terminated in the early morning hours. On the other hand, they feel extremely sleepy during the day [10]. Depression symptoms also include fatigue, dislike of activities, negativism and the physical appearance of 
these people is corresponding. Veraguth's fold (a fold in the nasal parts of upper eyelids) was also discovered, as well as oftentimes poor posture [13].

\section{Aim and Research Methods}

The aim of the research is to determine what approaches and methods are used in social work with depressed clients.

The research methods include the analysis of professional materials and case studies. In the first part of the research we have analyzed professional materials, focused on the methods of social work with depressed people. In the second part we present case studies, focused on the application of methods of social work with clients with depression. These case studies originate from our own past work experience as social workers in a rehabilitation center for people with psychical illnesses.

\section{Results}

Let's start by presenting the approaches and methods of social work, which are used when helping people with depression. Subsequently we will present three case studies, in which we apply selected methods.

\section{1. Approaches and Methods of Social Work with a Depressed Client Education}

It is important to explain to the depressed client that depression is a treatable condition. It is not his or her fault or the fault of anyone else. Depression causes the depletion of certain substances on nerve connections in the brain and frequent use of antidepressants gradually helps in achieving original balance. Furthermore, it is important to stress to the client to not compare given activity during depression and when he or she is not depressed. During depression, performance is naturally lower, so this is not about inability. With a lack of energy and focus, even a small task is more difficult than a daylong activity before.

It is also important to motivate the client not to resort to solitude, but to maintain contact with people close to him or her. Furthermore, it is important to support the client not to trust his or her negative thoughts. Thoughts during depression are skewed negatively. Should they arise, it is important either to think about something else or to not think about the by doing something else. Negative thoughts are part of depression and they disappear as depression subsides [14].

\section{Work as Medicine}

The depression symptoms also include loss of interest in anything that is happening, loss of motivation to engage in an activity and overall fatigue. Usually this happens in the morning after waking up. Even though the depressed person gets up after waking up, he or she rather go back to bed. It is a false idea to think that if a depressed person rests, he or she is gaining strength to manage the tasks awaiting him or her. The opposite is the truth. It appears that compared to a physically and mentally forced rest, the person gets tired by resting. After this excessive and inadequate rest, it is all the more difficult to get engaged in something.

The depressed person sometimes tells him or her self that he or she will wait until he or she will feel better. One can always wait. But the question is whether everything will get better all by itself. However, it is possible that if a person does engage in something (he or she will do some activity), his or her mood will improve and he or she will want to continue. To do something is the first step in the vicious circle of inactivity.

Sometimes the depressive person can say that it is too much, that it cannot be done under any circumstances. And sometimes it is indeed too much. It is not possible to move a large pile of sand all at one. However a lot of things can be done step by step. This is how long journeys are done.

What's the value of action in a depressive situation? It shifts the person's thoughts to a different thing, thus diverting him or her from that, which gets the person depressed. It gives him or her a reason to be happy about something - that he or she did something. To the contrary, if a person does something, he or she feels less tired and exhausted than if he or she would just sit, wait, do nothing and just stare. 
So what you have to try to do in depression? In a situation where everything that could be done seems to difficult, it is important to start with activities which brought joy to the person in the past (e. g. a walk in nature, garden work, reading, cleaning, etc.) It is also important to have a variety of activities, so that one activity doesn't become monotonous (e.g. instead of constant cleaning and cooking, the person can do garden work or some sport). It is also important to have a plan what to do. It is recommended to write a plan of activities in the evening for the following day, so that when a depressed person wakes up, he or she knows what to do and thus he or she gets ahead of thoughts about not doing anything. It is also encouraging to see what the person has already done. It is recommended to write down what was already done. If a client has a more demanding task ahead of him or her, it is important to lead him or her to split the task into smaller parts. It is also important for the client to rest between the parts and do something, which is more enjoyable that the given task. In order to improve a low self-esteem, it is good to choose certain activity (e. g. some hobby) and get better at it. The knowledge that a person can do something is the self-esteem booster [2, 14].

\section{Human Relationship as Medicine}

It is incredibly soothing to find a person, someone, who truly understands the depressed person. Perhaps because of this "the therapy by talking" is so effective at getting people out of depression. Making a friendship with someone is healing - there is someone here, the person in depression is not alone [15].

We try to convey to the client the experience that we can make it together. A depressed person needs enough time and patience from the social worker. During the discussion it is important to convey support and interest in participation on the discussion with the client. It is also recommended to be active in the discussion, because if the social worker has a passive attitude, so that the client is active, the client may perceive his or her own silence and lack of ideas as more incompetence and he or she will get even more depressed [16].

It is important for the social worker to set aside enough time for the discussion with the client and leave the client enough time and space to express him or herself. It is also important to support the client to relax emotionally and if possible, to cry. Even though humor is a good means of alleviating difficult situations, it is best not to use it with depressed clients, because they don't have an understanding in their condition and it can hurt them [17].

\section{Physical Exercise}

Lack of physical activity leads to the decay of the body. And not only that. The sympathetic system starts to dominate in a vegetative nervous system, which means that a body without physical activity starts experiencing stress. Lack of physical activity has an overall negative impact on human health. Metabolism cannot function naturally, which leads to fatigue and issues with heart and muscles. Regular physical activity is a good way how to avoid the physical consequences of stress. Physical strain burns excessive adrenaline, which leads to the increase of the activity of the parasympathetic system. Other positive effects include the slowing of cardiac activity, improved body posture and increased feeling of strength, health and wellbeing. After a physical exercise the mentally stressed person feels physically and mentally fresh. People, who don't do physical activity, are twice as likely to more from depressions and anxiety than people who do regular physical activity [18].

Exercises release endorphins in the brain, which cause the feeling of mental and physical wellbeing. The exercise doesn't have to be strenuous and energy-intensive. Stretching at home or just cleaning is enough. However, it is important to exercise at least 20 minutes a day [15].

\section{Ventilation}

The ventilation method is recommended for depressed people. This means encouraging them to speak out the thoughts, that plague them, and carefully listening to them. It appears that if a depressed person is encouraged to vent his or her emotional tension, the tension is then reduced. Therefore it is important to give them a chance to express their emotions - to vent them. Figuratively speaking - to open their heart or to pour out their heart and soul [2]. 


\section{The Stop Technique}

The basic idea of this technique is that if a client experiences negative thoughts, the client should say "stop!" and he or she should start to think about something positive and soothing. This is practiced as follows: To make the exercise easier, the client closes his or her eyes. He or she thinks of some everyday idea (e. g. walking down the street). He or she then says "stop!". He or she replaces the previous idea with a different one, which is more positive, soothing and calming (e. g. a meadow by a lake). After a while, he or she opens his or her eyes. The client repeats this several times. Subsequently the client continues to practice this with open eyes. He or she thinks about negative, depressive and unnerving thoughts. He or she then says "stop!". He or she then replaces this thought with a more positive one. At the beginning "stop!" is said out loud, after some training, it's enough to say "stop!" in his or her mind [19].

\section{Distraction}

Although the methods for distracting the client from unpleasant thoughts and emotions do not solve the causes of mental issues, they are important to manage the current situation, so that the person can control him or herself or to improve concentration. When a person gets an unnerving thought, he or she can distract him or herself from it by averting his or her attention to the outside world, to something positive or to some activity [20].

\section{Time to Worry/Worry-Chair}

One of the distraction methods is to postpone the unpleasant thoughts and worries for the future, e. g. "I will not deal with this now, I will worry about it in the evening at 7 p. m.". It is a method of time to worry/worry chair, when the person sets an exact time when to worry. [20].

\section{Planning Positive Activities}

In order to overcome the negative spiral of the decreasing number of pleasant activities and the deepening of anxiety, it is important to participate more and more on activities, which bring happiness and fulfillment to the depressed person. It is important to plan and then do these activities. At the beginning it is recommend selecting 1-2 positive activities for each day. Since anxiety can prevent the depressed person to fully experience these activities, we should not expect any extra emotionally experience or fulfillment. Even small happiness and relaxation are beneficial. This requires patience, because depressed people have to re-learn how to experience happiness [18].

Motivation for good performance arises rather through feedback than by willpower or some other phenomenon. Therefore, it is important for the client to note in his diary the things he or she successfully mastered and sometimes to return to these records [19].

\section{The Crisis Plan}

Some days are more demanding than others. It is therefore important to prepare oneself for the more demanding days, so that they will be more easily and safely handled [15].

When creating a crisis plan, it is important for the client to think about what difficult situations await him or her in the near future. Then he or she should work out a plan how to handle these situations as best as possible. The client should think about all the different reactions he or she might have, who or what could help him or her and how he or she will handle the stress the situation will present [14].

\section{Hope}

People need to have hope for a change for the better, if he or she will work on it. Especially for clients, who attempted suicide, it is of utmost importance to find hope. Hope, that despite their difficulties and their "crest of shards", they can contribute to the world in a meaningful way. Hope, that it is important what they do and that their actions affect the people around them. And, especially hope, that this task is prepared exclusively for them, that it is understandable and they can find it. All they have to do is to look for it [21]. 
Hope that things will get better is a feeling, giving strength and motivation to start acting and start working on oneself. If a person doesn't have hope, he or she feels helplessness and despair. An unrealistic hope is also a risk, because the person may experience disappointment, which can worsen his or her condition [20].

\section{Logotherapy - Searching for the Meaning of Life and Setting Out Goals}

Searching for the meaning of life is life's primary motivation. People strive for their lives to have a meaning; they are striving for a meaningful life. A person needs to find the meaning of life $[22,23]$.

A person who has a reason to live can stand almost anything. The founder of logotherary, V. E. Frankl, who spent years in concentration camps, writes that only those were able to survive the extreme situations in the concentration camp, who focused on the future, on the task ahead of them, on the meaning they wanted to fulfill [23, 24]. "If a person experiences his or her life as meaningless is not only unhappy, but barely vital. In fact, a person can survive only if he or she has something to live for" [22, p. 31].

The meaning of life is individual and differs from person to person and even from day to day. No psychotherapist or social worker can tell the client what is the meaning of his or her life. But he can assure him or her that his or her life has a meaning [23, 24].

The social worker should teach the client to look to the future, to a goal he or she could keep his or her eyes on. The client can set either a long-term goal, focus on a future goal, he or she could keep his or her eyes on, and thus gain mental strength, or even short-term goals: to have something to look forward to in the near future [23].

A person can also take upon him or herself a task, for which it is worth to use their life forces and which through its self-transcending way will make the person forgive about his or her own suffering. The person can find a path, where it is worth to use their life forces not for themselves, but for others [21].

The client could look for people, for who he or she could be important and needed. People, whom he or she could serve or help. The client should recognize that perhaps no one will come knocking on his or her door, but there are enough people outside needing his or her help. Happiness is not being well off, it means to be useful $[23,25]$.

\section{2. Study Cases - Application of Selected Methods}

The client is 29 years old, single and lives with her parents. In puberty she was diagnosed with a bipolar disorder with a predominant depressive episode. There is also a presence of suicidal tendencies. The client regularly visits a psychiatrist and she had also undergone psychiatric treatment. She is treated using pharmacological drugs and she uses them regularly. She is on a disability pension, she is not working. She visits a rehabilitation center for people with mental disorders.

The client came to us with the frustration that she is consumed by depression and she has suicidal thoughts. With this client we have used the logotherapy approach, where we were searching for a short-term positive goal she could focus on and which would give her a sense and a desire to live. The client came to the conclusion that during the upcoming weekend she plans to go hiking with her friends, to which she looks forward, because she likes her friends. This is how she was able to shift her thoughts to this upcoming positive goal, which helped her to overcome her current depression.

The client is 21 years old, she studies at a college, she is single and she lives in a dormitory. She suffers from depression since the secondary school. She tries to hide this from her environment, because she is afraid of stigmatization. She visits a psychiatrist only sporadically, she feels ashamed to take antidepressants. She comes to our rehabilitation center for people with mental disorders only during the time of her greatest crises, when she is not able to handle her states.

The client came to us in depression, saying she doesn't have the strength and cannot find a source of strength to fight her depressive states. She is also afraid, she will not be able to finish the college, she wants to finish, because she enjoys it. With this client we have used the ventilation method at first, where she talked about what burdens her and she described the states she expe- 
riences. We have taught the client how to manage negative thoughts and we explained to her the stop technique as well, where she learned how to stop unwanted thoughts. At the same time she was supposed to set aside enough time to talk to us again. In addition to the stop technique, she was supposed to use also the method of distracting herself from unnerving thoughts and focus on positive thoughts or activities.

The client is 52 years old, he lives with her mother. He is on a disability pension. He suffers from depression and has other health issues. He regularly visits a psychiatrist and does not have an issue with pharmacological treatment.

The client often complaints of boredom, which often leads him into his inner depressive world. With this client we focused on searching for positive activities and meaningful activities, so that he can effectively spend his leisure time and find happiness and inner fulfillment in this activity. The client likes nature and in the past he was a hiker, so he decided to take on hiking again. We have helped the client to find a tourist club, where together with his peers he is able to visit different tourist places. The client enjoyed this club and after some time he started to help out in this club as a volunteer - he plans new tourist trips and helps with the promotion of this club. This volunteering activity also brings him a feeling of meaningfulness and usefulness.

\section{Conclusion}

1. There are healthcare and social services for people with mental disorders. The field of social services includes services, which are primarily focused on people with mental disorders. However, there are people in social services facilities, which are not primarily focused on people with mental disorders, which do suffer from mental disorders (often due to the placement in such facility). Therefore, it is necessary for the social workers to know mental disorders, know their diagnostic criteria, symptoms and especially means of help.

2. Depression is an especially important mental illness due to its frequent occurrence. Metaphorically, we can say about depression that "depression is like a black dog, who sat on you" $[19$, p. 102]. Or, in the words of Atkinson [15, p. 17]: "depression is a thick fog, which suddenly envelops the person".

3. Social work has approaches and methods, which are effective in helping people in depression. We have introduced the following approaches and methods: education, work as a medicine, human relationship as a medicine, physical exercise, ventilation, the stop technique, distraction, time to worry, the planning of positive activities, the crisis plan, hope, logotherapy - searching for the meaning of life and setting out goals.

\section{References}

[1] International classification of diseases. National Health Information Center. Available at: http://www.nczisk.sk/Standardy-v-zdravotnictve/Pages/Medzinarodna-klasifikacia-chorob-MKCH-10. aspx Last accessed: 17.02.2019

[2] Křivohlavý, J. (2013). How to manage depression. Prague: Grada, 184.

[3] Röhr, H. P. (2012). Paths from anxiety and depression. About the happiness of loving oneself. Prague: Portál, 168.

[4] Vavrušová, L. et. al. (Eds.) (2008). Depression. Martin: Osveta, 220.

[5] Grün, A. (2009). Depression as a chance. Spiritual impulses. Prague: Portál, 136.

[6] Dušek, K., Večeřová-Procházková, A. (2017). Diagnostics and therapy of mental disorders. Prague: Grada, 648.

[7] Raboch, J., Pavlovský, P. et. al. (2008). Clinical psychiatry in daily practice. Prague: Galen, 158.

[8] Gay, C. (2010). Bipolar disorder. Advice for the families and relatives of people with manic depressions. Prague: Portál, 136.

[9] Mentzos, S. (2005). The dynamics of a mental disorder. Prague: Portál, 127.

[10] Látalová, K. (2010). Bipolar affective disorder. Prague: Grada, 256.

[11] Styx, P. (2003). About psychiatry. How to live and deal with mentally ill people. Brno: Computer Press, 178. 
[12] Raboch, J., Pavlovský, P., Janotová, D. (2012). Psychiatry - minimum for practice. Prague: Triton, 239.

[13] Kafka, J. et. al. (1998). Psychiatry. Textbook for medical faculties. Martin: Osveta, 255.

[14] Praško, J., Prašková, H., Prašková, J. (2003). Depression and how to manage it. Prague: Portál, 184.

[15] Atkinsonová, S. (2005). How to climb the rock of depression. Prague: Albatros, 155.

[16] Probstová, V., Pěč, O. (2014). Psychiatry for social workers. Selected chapters. Prague: Portál, 248.

[17] Honzák, R. (1999). Depression. A depressed patient in a non-psychiatric clinic. Prague: Gallén, 109.

[18] Praško, J., Vyskočilová, J., Prašková, J. (2012). Anxiety and concerns. How to overcome them. Prague: Portál, 232.

[19] Novák, T., Lásková, H. (2016). Hell in soul. Depression and mania. Prague: Grada, 144.

[20] Pešek, R. (2018). Psychiatrist to oneself or What truly helps in managing anxiety and depression. The perspective of cognitive behavioral therapy. Prague: Pasparta, 108.

[21] Lukasová, E. (2012). The key to a meaningful life. Bratislava: Lúč, 360.

[22] Frankl, V. E. (2010). Will to a sense. Bratislava: Lúč, 279.

[23] Frankl, V. E. (2011). Looking for the meaning of life. Tell yes to despite it all. Bratislava: Eastone Books, 131.

[24] Frankl, V. E. (2016). Suffering from the meaninglessness of life. Psychotherapy for today. Prague: Portál, 128.

[25] Lukasová, E. (2009). Basics of logotherapy. Bratislava: Lúč, 276. 